\title{
A Comparison of the Physiological Age of Adult Resting Versus Flying Culex quinquefasciatus (Diptera: Culicidae)
}

\author{
D.M. Roberts
}

Department of Biology, College of Science, Sultan Qaboos University, P.O. Box 36, Postal code 123, Muscat, Sultanate of Oman, Email: derekmr@squ.edu.om.

\author{
ـقارنة بين الهمر الفسيولوجي للبعوض (الكيولكس كيوبكوفلسيا) وهوفطور اللكهن بقارنة بحالة الليرلن
}

$$
\text { טيرك روبرتس }
$$

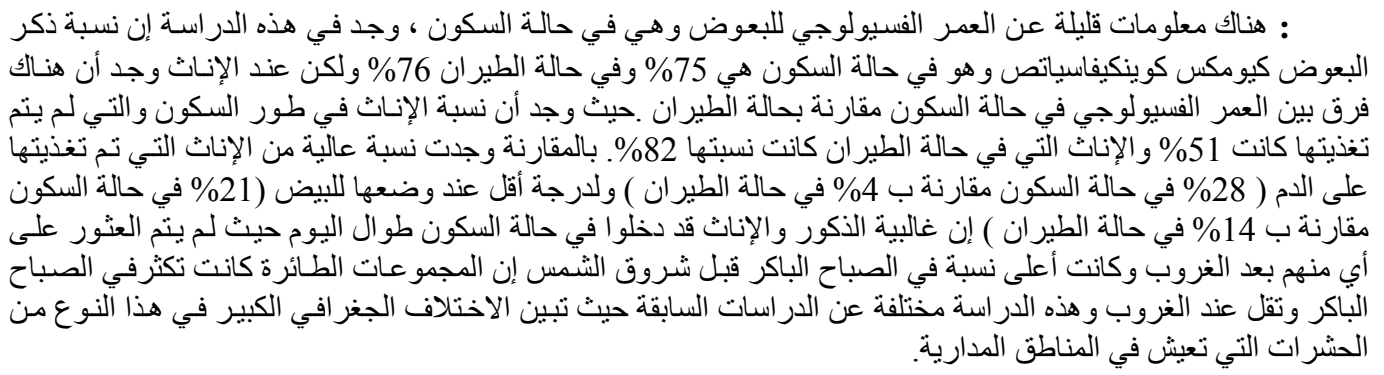

ABSTRACT: Relatively little is known about the physiological age of resting mosquitoes. In this study, Culex quinquefasciatus had a similar proportion of resting males (75\%) as in the flying population $(76 \%)$, but among the females, there were significant differences between the physiological age of the resting and flying populations. The proportion of unfed resting females (51\%) made up a significantly smaller proportion than in the flying female group (82\%). By contrast, in the resting group, there were much higher proportions of blood-fed $(28 \%$ compared with $4 \%$ ) and to a lesser extent gravid (21\% compared with $14 \%$ ) females. Of the blood-fed females, most of the resting individuals were freshly blood-fed. Both males and females entered the resting traps throughout the day (but none were collected after sunset), with the main peak around dawn. The flying population showed two circadian peaks: a larger peak at dawn and smaller peak after sunset. This indicates a different pattern from that shown in other studies and demonstrates the significant geographic variation within this pan-tropical species.

KEYWORDS: Culex quinquefasciatus, Mosquitoes, Circadian activity, Resting, Flight activity. 


\section{Introduction}

$\mathbf{T}$

The female mosquito has up to 8 gonotrophic cycles, each averaging 4 - 4.5 days (Birley and Rajagopalan, 1981; Chandra et al., 1996), although Subra (1981) found this varied on different cycles. During each of these cycles, the female needs to find a blood meal, digest the blood meal and develop its eggs, and then find somewhere to oviposit the eggs. Its behaviour thus changes during different stages of the cycle and its need for somewhere to rest will thus similarly change.

Although there have been many studies of circadian flying activity in $C x$. quinquefasciatus from different parts of the world , there have been few studies of resting behaviour and particularly the effect of physiological age on this behaviour.

By emptying artificial resting-site traps at different times of the day, the resting behaviour of the mosquitoes was compared with their circadian flight activity, studied using suction traps. A further experiment investigated how easily each group of resting mosquitoes were disturbed and thus left the trap during the day.

\section{Materials and Methods}

Two suction traps and 10 resting-site traps were placed in a suburban garden, at least $10 \mathrm{~m}$ apart, in the town of Al-Khod on the Batinah coast of Oman. All the mosquitoes collected were identified as $C x$. quinquefasciatus and no other mosquito species were found in the urban area. This is probably because there was no surface water within 10 kilometres of the site and no rain during the collecting period (or for many months beforehand). Thus virtually the only available breeding waters were in the septic tanks of the surrounding houses, which are the major breeding sites for $C x$. quinquefasciatus.

Each suction trap had a $33 \mathrm{~cm}$ fan sucking air through a wire net cone and depositing the insects into a jar containing ethanol. The artificial resting sites each consisted of a thick plastic bag with dimensions of $85(\mathrm{~h}) \mathrm{x}$ 50 (l) x 24 (w) cm. Each bag was black internally and light-proof, thus fitting Morris' (1981) ideal characteristics of a resting trap. The traps were attached to trees, so that their open tops were about the same height above ground $(1.5 \mathrm{~m})$ as the suction trap entrances. The resting-site bags were emptied by rapidly repeatedly sweeping a net through the bag, until no more mosquitoes emerged.

Although $C x$ quinquefasciatus is present throughout the year, due to the extreme climatic conditions of Oman with daytime temperature over $40{ }^{\circ} \mathrm{C}$ for 5 months of the year, the mosquitoes were only sufficiently abundant for the experiments for 3 months during the winter.

In the first two experiments, which were run consecutively in Feb. 2004, both suction traps (to monitor the flying insects) and resting traps were emptied 7 times a day to give 7 daily samples: late night $=23.00 \mathrm{~h}$ to $6.00 \mathrm{~h}$ ( $7 \mathrm{~h}$ ); early dawn $=6.00 \mathrm{~h}$ (which was $1^{\text {st }}$ light with $<100$ lux) to $6.30 \mathrm{~h}(0.5 \mathrm{~h}$ ); late dawn $=6.30 \mathrm{~h}$ to $7.00 \mathrm{~h}$ (by which time, the light intensity was $>100,000$ lux $)(0.5 \mathrm{~h})$; day $=7.00 \mathrm{~h}$ to $18.00 \mathrm{~h}(11 \mathrm{~h})$; early sunset $=18.00$ to $18.30 \mathrm{~h}(0.5 \mathrm{~h})$; late sunset $=18.30 \mathrm{~h}$ (sunset) to $19.00 \mathrm{~h}(0.5 \mathrm{~h})$; and early night $=19.00 \mathrm{~h}$ to $23.00 \mathrm{~h}(4 \mathrm{~h})$. In the second experiment, the two sunset catches (early + late) were combined, due to their very small size. The first experiment had 15 replicates (i.e. 15 consecutive days), but the other 3 experiments using resting traps were reduced to 10 replicates each due to the large mosquito catches.

In the third experiment (early March 2004), 10 resting traps were left for $24 \mathrm{~h}$ and only emptied after dawn $(7.00 \mathrm{~h})$, while a further 10 resting traps were emptied at sunset each day $(18.30 \mathrm{~h})$, in order to see whether a particular mosquito group (sex/ physiological age or blood-fed stage) was more sensitive to mechanical disturbance by wind during the day.

All the female mosquitoes were dissected under an insect saline solution $(8.5 \mathrm{~g} \mathrm{NaCl} / 1)$ in order to identify their physiological state. They were divided into unfed, blood-fed and gravid. The blood-fed females were further subdivided by the stage of oocyte development into type I, II, III and IV (type V being gravid). Initially, the unfed and blood-fed individuals were also divided into nulliparous and parous. However, for logistical reasons, half the mosquitoes were not dissected until a year later, by which time they had deteriorated too much to permit separation by age. 


\section{Results}

Table 1. Composition of the mosquito catch in the suction traps (flying insects) and the resting traps.

\begin{tabular}{|c|c|c|c|c|}
\hline & \multicolumn{2}{|c|}{ Flying insects (Suction trap) } & \multicolumn{2}{|c|}{ Resting insects } \\
\hline & Total & $\%$ catch & Total & $\%$ catch \\
\hline Males & 18,334 & $76 \%$ & 8,184 & $75 \%$ \\
\hline Females & 5,666 & 24 & 2,748 & 25 \\
\hline Unfed & $4,656 \mathrm{c}$ & $82 \% *$ & $1,392 \mathrm{a}$ & $51 \% *$ \\
\hline Bloodfed & $249 \mathrm{~d}$ & 4 & $766 \mathrm{~b}$ & 28 \\
\hline Gravid & $761 \mathrm{e}$ & 14 & $589 \mathrm{~b}$ & 21 \\
\hline Bloodfed 1 & $67 \mathrm{~h}$ & $27 \% * *$ & $279 \mathrm{f}$ & $36 \% * *$ \\
\hline BF $2+3$ & $89 \mathrm{gh}$ & 36 & $266 \mathrm{f}$ & 35 \\
\hline BF 4 & $93 \mathrm{~g}$ & 37 & $221 \mathrm{f}$ & 29 \\
\hline$* \%$ of females & $* * \%$ of & & & \\
\hline
\end{tabular}

In the suction traps, flying mosquitoes showed a much greater level of activity in the males (making up $76 \%$ of the catch, Table 1) than in the females. Males, however, were mainly restricted to a large dawn and smaller sunset peak, while the females had smaller peaks, due to a higher level of activity throughout the night (Figure 1).

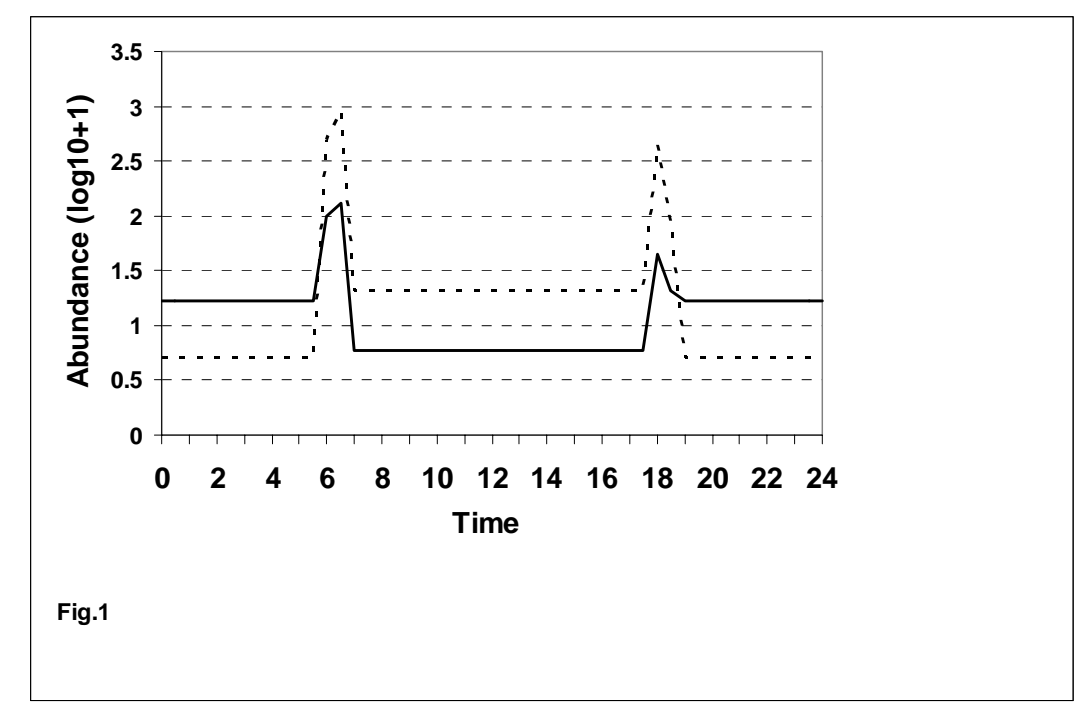

Figure 1. Circadian activity of flying males and females. - - - males; females. 


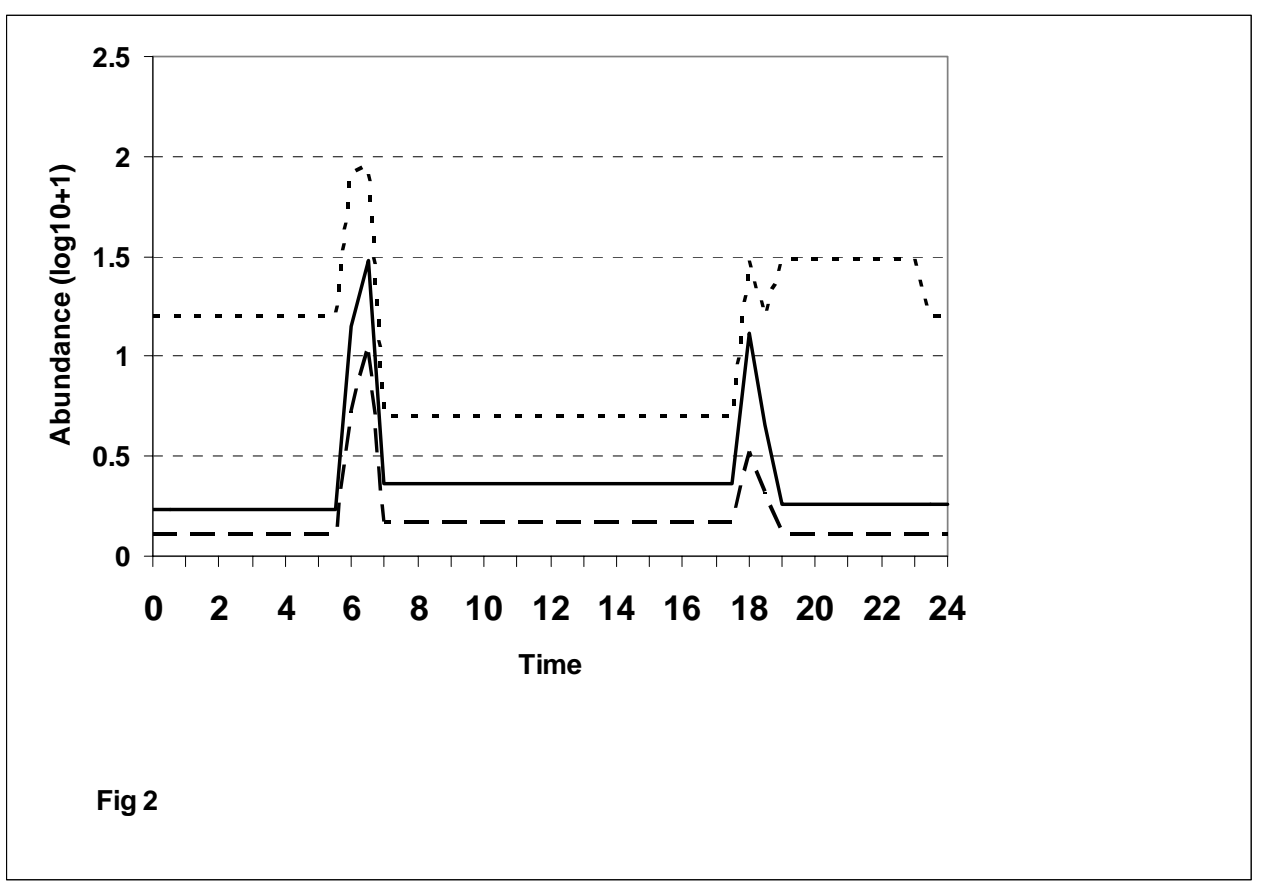

Figure 2. Circadian activity of flying females. - - - - Unfed; -- -- -- Blood-fed; Gravid.

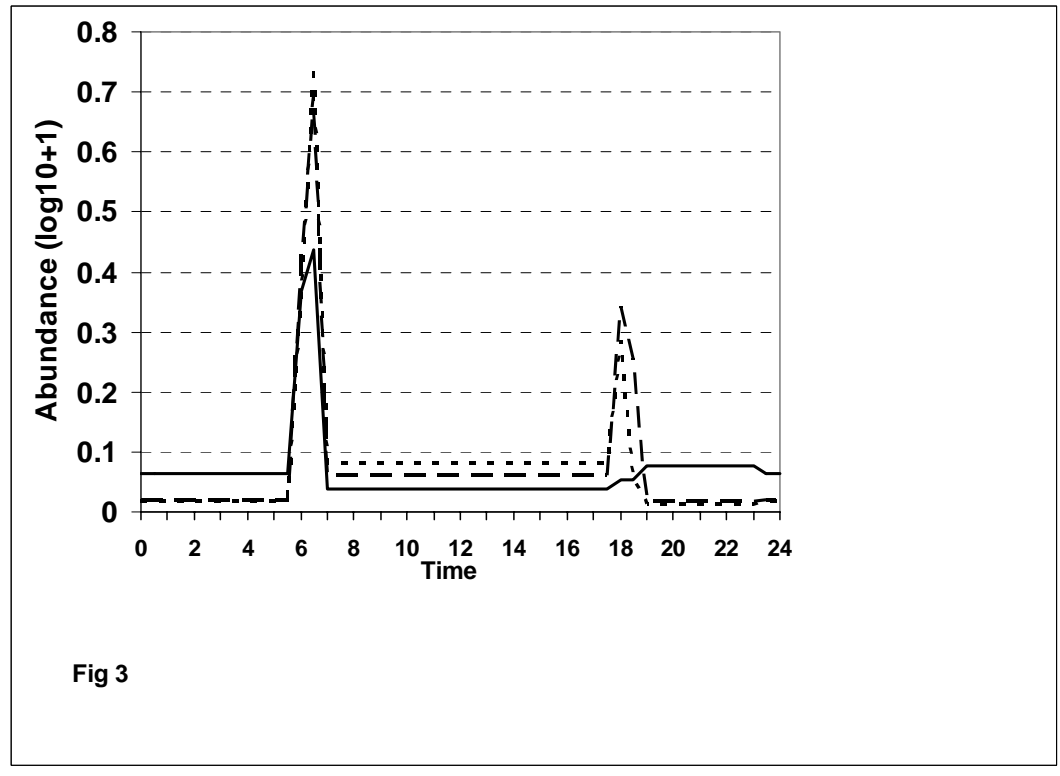

Figure 3. Circadian activity of flying blood-fed females. Stage 4.

Stage $1 ;$-- -- -- Stage 2+3; - - - 


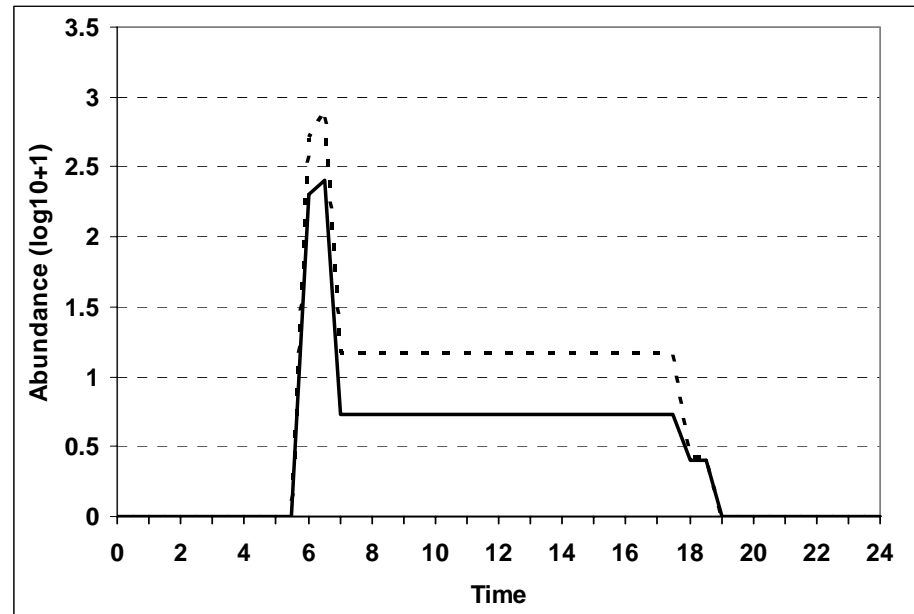

Fig 4

Figure 4. Circadian resting activity of males and females. - - - Males; females.

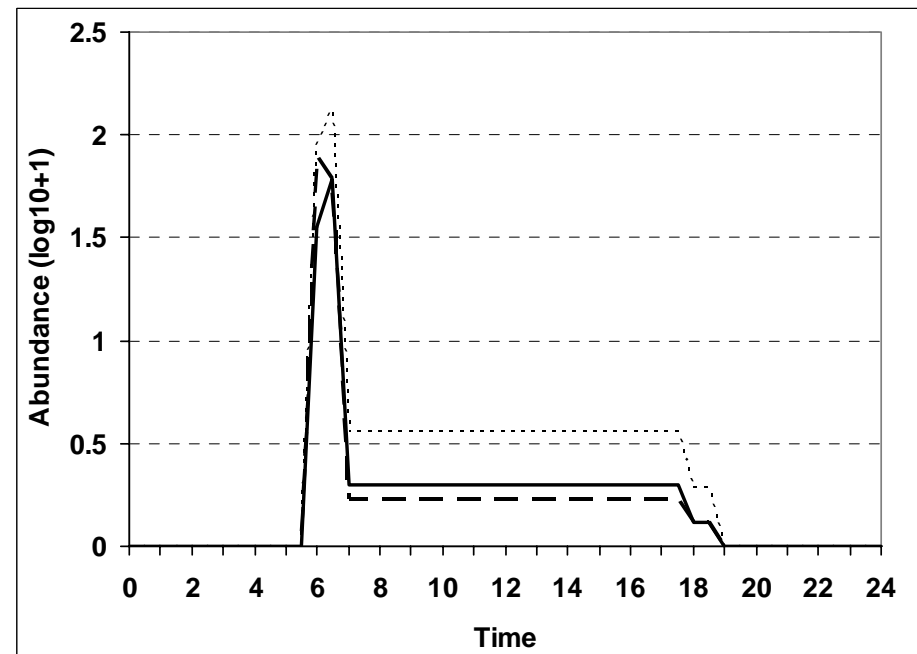

Fig 5.

Figure 5. Circadian resting activity of female groups. - - - - Unfed; -- -- -- Blood-fed; Gravid.

Among the flying females, most (82\%) were unfed (Table1) and showed the activity pattern above (Figure 2), but the small numbers of gravid and very small (4\%) numbers of blood-fed females had their activity 


\section{D.M. ROBERTS}

largely restricted to the large dawn and smaller sunset peaks. When the blood-fed females were subdivided by their physiological age, the freshly blood-fed (stage 1) were significantly less abundant $(\mathrm{p}=0.018$ in a 1 -way ANOVA) than the stage 4 females. In addition, they differed from the others by having activity throughout the night, but no sunset peak (Figure 3).

The resting mosquitoes had virtually the same sex ratio ( $75 \%$ males) as the flying ones ( $76 \%$ - Table 1$)$. Both males and females had a similar pattern of entering the resting traps at dawn (Figure 4). Small numbers continued to enter during the day, with the females in this group being almost entirely unfed (Figure 5), but at night the traps did not attract mosquitoes. Among the females, only $51 \%$ were unfed (Table 1 ), but there was a significantly ( $p<0.0001$ on a 2 -way ANOVA) greater proportion of blood-fed females $(28 \%)$ and to a lesser extent gravid females compared with the flying population. The blood-fed resting females, compared with those flying, had a significantly greater $(p=0.025)$ proportion of freshly blood-fed (stage 1 oocytes) females (Tukey test in Table 1).

Table 2. Comparison of resting mosquitoes collected at dawn and at dusk.

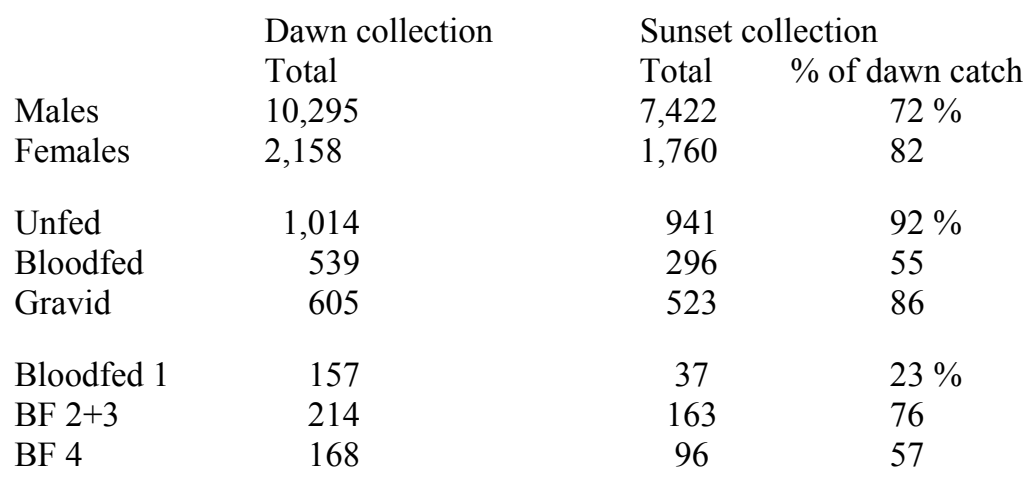

When resting mosquitoes were left until sunset before being collected (Table 2), the number declined to $82 \%$ of the dawn catch for the females and $72 \%$ for the males. Among the females, the decline was greatest among the blood-fed ( $45 \%$ had gone by sunset), with only a very small decrease ( $8 \%$ ) for the unfed flies. Among the blood-fed females, the biggest decrease was in the freshly fed (Stage I) females.

\section{Discussion}

When considering the activity patterns of male and female $C x$ quinquefasciatus, both had two peaks: before sunrise and after sunset. The females, however, had much more extensive activity than the males and were active throughout the night. They even showed some activity during the daytime. Both sexes had their main peak at dawn and a much smaller sunset peak. A similar result was found in laboratory studies by Jones (1982), and also for studies on the Cx quinquefasciatus sibling species: Cx molestus Forskal and Cx pallens Coquillet (Shinkawa et al., 1994) and Cx pipiens L. (Caglar et al., 2003).

However, other studies have shown considerable variation in the circadian activity of Cx quinquefasciatus, although most were limited to biting catches and therefore represent only a small part of the female population. Some studies have found that biting activity of $C x$ quinquefasciatus was greatest in the early part of the night (Gowda and Viayan, 1993; Khan et al., 1997; Pipitgool et al, 1998), while others found activity greatest after midnight (Brunhes, 1975; Subra, 1981; Vanamail and Ramaiah, 1991; Ramasamy et al, 1994; Chandra, 2001). In still other studies, however, two peaks of activity were recorded. For example Mahanta et al. (1999) found peaks around 19.00 and 23.00h; Yee and Foster (1992) found peaks at 23.00h and before dawn, while Sucharit et al. (1981) found three peaks. 


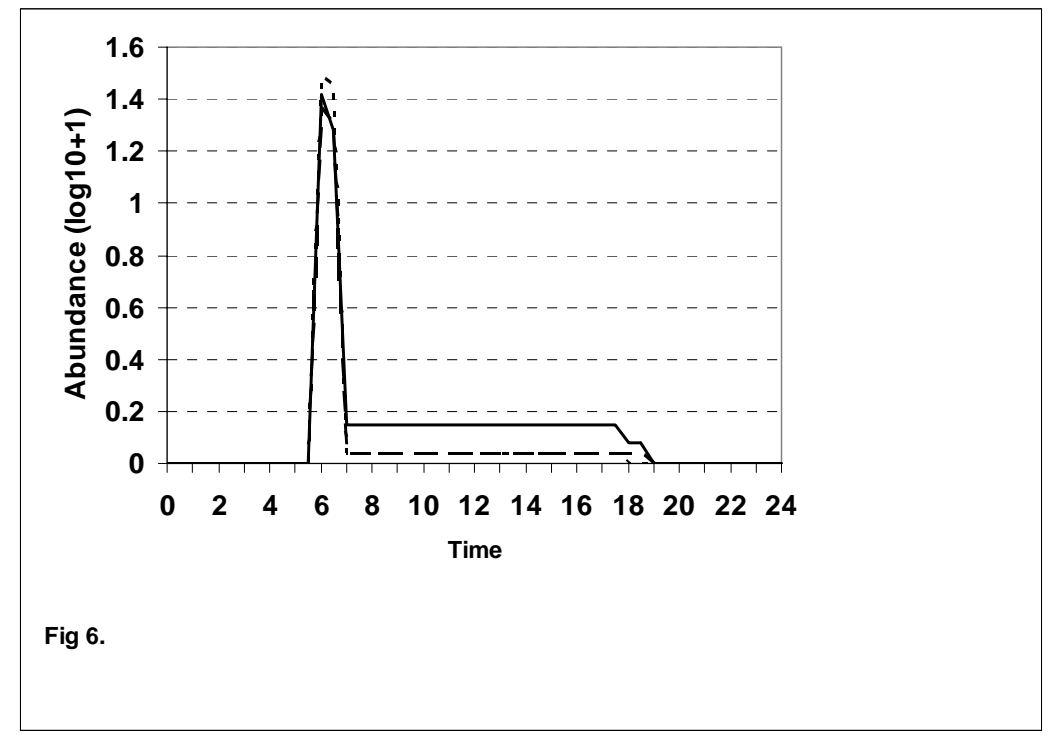

Figure 6. Circadian resting activity of blood-fed females. - - - Stage 1; Stage $2+3 ;------$ Stage 4.

The fact that gravid females, which are likely to be looking for oviposition sites, had dawn and sunset peaks corresponds to the results of oviposition behaviour observations by Hayes and Downs (1980) and Subra (1981). However, other studies have shown considerable differences from this pattern. Thus Beehler et al. (1993) found that oviposition occurred mainly within 2 hours after sunset, but extended up to midnight. Suleman and Shirin (1981) found a midnight peak, while Panicker et al. (1981) found a peak after midnight.

These variations observed by different workers in different parts of the world, when studying the flight, biting and oviposition cycles of $C x$ quinquefasciatus are likely to be due to the pantropical distribution of the species, with resulting racial genetic variations in different regions, and they demonstrate the importance of regional studies when trying to understand the ecology of the vector of filariasis and viral diseases.

The resting females, when compared with the active flying population, had a significantly higher proportion of blood-fed individuals, especially those freshly blood-fed with stage 1 oocytes, showing their need to rest while digesting the meal. There was also a greater proportion of resting gravid females than in the active population, but many non-fed females were also collected. The fact that all the female stages were present in large numbers in these outdoor resting sites contrasts with other studies. Thus Subra (1970), studying an area of traditional huts, found a high proportion of freshly fed resting females inside the huts, but outside resting sites (wells) mainly had non-fed and gravid females. From this, he concluded that the mosquitoes mainly fed indoors and remained resting indoors to digest their meal. They then moved outdoors to lay their eggs and remained outdoors until ready to blood-feed again. Similar conclusions were made by Service (1963) and Kulkarni and Rajput (1988). However, in the present urban study, where all houses have window mosquito netting and airconditioning, endophagic feeding would be more normal and thus a high proportion of the resting females outdoors were freshly fed. Tuno et al. (2003) considered that non-fed mosquitoes rested near their host before deciding whether to blood-feed and this could partly account for the large numbers of resting non-fed females collected in this study.

This would lead to a cycle in which females rested before feeding (making up 51\% of the resting females), but after blood-feeding still spent most of their cycle resting while their eggs developed ( $28 \%$ blood-fed and $21 \%$ gravid). When the resting traps were emptied at sunset, rather than dawn, the decline in population was greatest among the freshly blood-fed, showing that they were more likely to be disturbed and move on to a better resting 
site, whereas the unfed and gravid females were much less likely to be disturbed from their resting behaviour. This disturbance is most likely due to the wind, since the traps were in deep shade and so unlikely to get hot during the winter months.

Male mosquitoes were much more abundant than females in both the resting traps $(75 \%)$ and among the flying population (76\%), although emerging Cx quinquefasciatus have an equal sex ratio. Schreiber et al. (1993) found a lower ratio of $61 \%$ resting $C x$. quinquefasciatus to be male. He concluded that the males were less active than the females and that his traps were close to the breeding sites. However in this study with abundant breeding sites, it is more likely that the resting traps were more attractive to the males and, by observation, the males swarmed around the suction traps, which thus collected more males than females

\section{Acknowledgements}

I thank Sultan Qaboos University for providing research facilities.

\section{References}

ABU HASSAN, A., NARAYANAN, V. and SALMAH, M.R.C. 1993. Observations on the physico-chemical factors of the breeding habitats of Culex quinquefasciatus Say, 1823 (Diptera: Culicidae) in towns of North Western Peninsular Malaysia. Ann. Med. Entomol., 2: 1-5.

BEEHLER, J.W., WEBB, J.P. and MULLA, M.S. 1993. Spatial and circadian oviposition patterns in an urban population of Culex quinquefasciatus. J. Am. Mosq. Control Assoc., 9: 385-388.

BIRLEY, M.H. and RAJAGOPALAN, P.K. 1981. Estimation of the survival and biting rates of Culex quinquefasciatus (Diptera: Culicidae). J. Med. Entomol., 18: 181-186.

BRUNHES, J. 1975. La filiarose de Bancroft dans les sous-region malgache (Comores-Madagascar-Reunion). Memoires ORSTOM, 81: 1-212.

CAGLAR, S.S., ALTEN, B., BELLINI, R., SIMSEK, F.M. and KAYNAS, S. 2003. Comparison of nocturnal activities of mosquitoes (Diptera: Culicidae) sampled by New Jersey light traps and $\mathrm{CO}_{2}$ traps in Belek, Turkey. J. Vector Ecol., 28: 1-11.

CHANDRA, G., SEAL, B. and HATI, A.K. 1996. Age composition of the filarial vector Culex quinquefasciatus (Diptera: Culicidae) in Calcutta, India. Bull. Entomol. Res,. 86: 223-226.

CHANDRA, G. 2001. Man biting activity of filarial vector Culex quinquefasciatus. J. Comm. Dis., 33: 53-57.

CHAVASSE, D.C., LINES, J.D., ICHIMORI, K. and MARIJANI, J. 1995. Mosquito control in Dar es Salaam. I Assessment of Culex quinquefasciatus breeding sites prior to intervention. Med. Vet. Entomol., 9: 141-146.

GOWDA, N.N. and VIAYAN, V.A. 1993. Biting density, behaviour and age distribution of Culex quinquefasciatus Say in Mysore city, India. S.E. Asian J. Trop. Med. Public Hlth., 24: 152-156.

HAYES, J. and DOWNES, T.D. 1980. Seasonal changes in an isolated population of Culex pipiens quinquefasciatus (Diptera: Culicidae): a time series analysis. J. Med. Entomol., 17: 63-69.

JONES, M.D.R. 1982. Coupled oscillators controlling circadian flight activity in the mosquito, Culex pipiens quinquefasciatus. Physiol. Entomol., 7: 281-289.

KHAN, S.A., NARAIN, K., DUTTA, P., HANDIQUE, R., SRIVASTAVA, V.K. and MAHANTA, J. 1997. Biting behaviour and biting rhythm of potential Japanese encephalitis vectors in Assam. J. Comm. Dis., 29: 109-120.

KULKHANI, S.M. and RAJPUT, K.B. 1988. Day-time resting habitats of Culicine mosquitoes and their preponderance in Bastar District, Madhya Pradesh, India. J. Comm. Dis., 20: 280-286.

MAHANTA, B, HANDIQUE, R., DUTTA, P., NARAIN, K. and MAHANTA, J. 1999. Temporal variations in biting density and rhythm of Culex quinquefasciatus in tea agro-ecosystem of Assam, India. S.E. Asian J. Trop. Med. Public Hlth., 30: 804-809. 
MENON, P.K.B. and RAJAGOPALAN, P.K. 1980. Relative importance of different types of breeding habitats in contributing to the population of Culex pipiens fatigans in Pondicherry. Indian J. Med. Res., 71: 725733.

MORRIS, C.D. 1981. A structural and operational analysis of diurnal resting shelters for mosquitoes (Diptera: Culicidae). J. Med. Entomol., 18: 419-424.

PANICKER, K.N., BAI, M.G. and VISWAM, K. 1981. Observations on the oviposition rhythm of some mosquitoes. Indian J. Med. Res., 74: 388-391.

PIPITGOOL, V., WAREE, P., SITHITHAWORN, P. and LIMVIROJ, W. 1998. Studies on biting density and biting cycle of Culex quinquefasciatus, Say in Khon Kaen city, Thailand. S.E. Asian J. Trop. Med. Public Hlth., 29: 333-336.

RAMASAMY, M.S., KULASEKERA, R., SRIKRISHNARAJ, K.A. and RAMASAMY, R. 1994. Population dynamics of anthropophilic mosquitoes during the northeast monsoon season in the malaria epidemic zone of Sri Lanka. Med. Vet. Entomol., 8: 265-274.

ROBERTS, D.M. and IRVING-BELL, R.J. 1997. Salinity and microhabitat preferences in mosquito larvae from southern Oman. J. Arid Environ., 37: 497-504.

SCHREIBER, E.T., WALTON, W.E. and MULLA, M.S. 1993. Mosquito utilisation of resting sites at an urban residence in southern California. Bull. Soc. Vector Ecol., 18: 152-159.

SERVICE, M.W. 1963. The ecology of the mosquitoes of the northern Guinea savannah of Nigeria. Bull. Entomol. Res,. 54: 601-632.

SHINKAWA, Y., TAKEDA, S., TOMIOKA, K., MATSUMOTO, A., ODA, T. and CHIBA, Y. 1994. Variability in circadian activity patterns within the Culex pipiens complex (Diptera: Culicidae). J. Med. Entomol., 31: 49-56.

SINHA, V.P. 1976. Further observations on the physico-chemical factors of the breeding places of Culex quinquefasciatus Say = fatigans Wied. Mosq. News, 36: 358-360.

SUBRA, R. 1970. Etude ecologiques sur Culex pipiens fatigans Wiedemann, 1828, (Diptera, Culicidae) dans une zone urbaine de savane soudanienne ouest-africaine. Dynamique des populations preimaginales. Cah. ORSTOM serie Entomol. Med. Parasitol., 8: 353-376.

SUBRA, R. 1981. Biology and control of Culex pipiens quinquefasciatus Say, 1823, (Diptera: Culicidae) with special reference to Africa. Insect Sc. Applic., 1: 319-338.

SUBRA, R. 1982. The distribution and frequency of Culex pipiens quinquefasciatus Say 1823 (Diptera: Culicidae) breeding places on the Kenya coast in relation to human sociological factors. J. Trop. Med. Hygiene, 85: 57-61.

SUCHARIT, S., HARINASUTA, C., SURATHIN, K., DEESIN, T., VUTIKES, S. and RONGSRIYAM, Y. 1981. Some aspects of biting cycles of Culex quinquefasciatus in Bangkok, Thailand. S.E. Asian J. Trop. Med. Public Hlth., 12: 75-78.

SULEMAN, M. and SHIRIN, M. 1981. Laboratory studies on oviposition behaviour of Culex quinquefasciatus Say (Diptera: Culicidae): choice of oviposition medium and oviposition cycle. Bull. Entomol. Res,. 71: 361-369.

TUNO, N., TSUDA, Y., TAKAGI, M. and SWONKERD, W. 2003. Pre- and postprandial mosquito resting behaviour around cattle hosts. J. Am. Mosq. Control Assoc.,19: 211-219.

VANAMAIL, P and RAMAIAH, K.D. 1991. Biting periodicity index of Culex quinquefasciatus and its relationship with microfilaria periodicity in Pondicherry. Indian J. Med. Res., 93: 379-383.

YEE, W.L. and WOODBRIDGE, A.F. 1992. Diel sugar-feeding and host-seeking rhythms in mosquitoes (Diptera: Culicidae) under laboratory conditions. J. Med. Entomol., 29: 784-791.

Received 31 March 2009

Accepted 30 January 2010 